\title{
A non-human primate model of familial Alzheimer's disease for translational medicine
}

\section{Kenya Sato}

Central Institute for Experimental Animals

\section{Hiiroki Sasaguri}

RIKEN Center for Brain Science

Kumita Wakako

Central Institute for Experimental Animals

Yoiko Kurotani

Central Institute for Experimental Animals

Takeshi Inoue

Central Institute for Experimental Animals

Kennichi Nagata

Nagoya University Graduate School of Medicine

Naomi Mihira

RIKEN Center for Brain Science

\section{Kaori Sato}

RIKEN Center for Brain Science

\section{Tetsushi Sakuma}

Hiroshima University

\section{Takashi Yamamoto}

Hiroshima University

\section{Michihira Tagami}

RIKEN Center for Integrative Medical Sciences

Manabe Ri-ichiroh

RIKEN Center for Integrative Medical Sciences

\section{Kokoro Ozaki}

RIKEN Center for Integrative Medical Sciences

Yasushi Okazaki

RIKEN Center for Integrative Medical Sciences

Takaomi Saido ( $\nabla$ saido@brain.riken.jp )

RIKEN Center for Brain Science https://orcid.org/0000-0003-1970-6903

\section{Erika Sasaki}

Central Institute for Experimental Animals 
Article

Keywords: Alzheimer's disease, genome editing

Posted Date: March 12th, 2021

DOl: https://doi.org/10.21203/rs.3.rs-265068/v1

License: (c) (i) This work is licensed under a Creative Commons Attribution 4.0 International License. Read Full License 


\section{A non-human primate model of familial Alzheimer's disease for translational medicine}

Kenya Sato ${ }^{1,2, \dagger}$, Hiroki Sasaguri ${ }^{2 \dagger}$, Wakako Kumita ${ }^{1,2}$, Takashi Inoue ${ }^{1}$, Yoko Kurotaki ${ }^{3}$, Kenichi Nagata $^{2}$, Naomi Mihira ${ }^{2}$, Kaori Sato ${ }^{2}$, Tetsushi Sakuma ${ }^{4}$, Takashi Yamamoto ${ }^{4}$, Michihira Tagami ${ }^{5}$, Riichiroh Manabe ${ }^{5}$, Kokoro Ozaki ${ }^{5}$, Yasushi Okazaki ${ }^{5}$, Takaomi C. Saido ${ }^{2, *}$ and Erika Sasaki ${ }^{1,2,6, *}$

${ }^{1}$ Department of Marmoset Biology and Medicine, Central Institute for Experimental Animals, 3-2512 Tonomachi, Kawasaki, Kanagawa, JAPAN.

${ }^{2}$ Laboratory for Proteolytic Neuroscience, RIKEN Center for Brain Science, 2-1 Hirosawa, Wako-shi, Saitama, JAPAN.

${ }^{3}$ Center of Basic Technology in Marmoset, Central Institute for Experimental Animals, 3-25-12 Tonomachi, Kawasaki, Kanagawa, JAPAN.

${ }^{4}$ Graduate School of Integrated Sciences for Life, Hiroshima University, 1-3-1 Kagamiyama, HigashiHiroshima-shi, Hiroshima, JAPAN.

${ }^{5}$ Laboratory for Comprehensive Genomic Analysis, RIKEN Center for Integrative Medical Science, 1-7-22 Suehiro-cho, Tsurumi-ku, Yokohama, Kanagawa, JAPAN.

${ }^{6}$ Laboratory for Marmoset Neural Architecture, RIKEN Center for Brain Science, Saitama 3510198, Japan.

${ }^{\dagger}$ These authors contributed equally to this work.

*Corresponding authors: saido@brain.riken.jp; esasaki@ciea.or.jp 


\section{Summary}

Aging is a primary risk factor of Alzheimer's disease (AD), with the world-wide number of patients anticipated shortly to exceed 50 million. Despite extensive research efforts, no effective measures are available for its prevention or treatment due in part to a lack of human-like animal models. Here, we describe the generation of three mutant marmoset individuals in which exon 9 of the PSEN1 gene product is deleted (PSEN1- $\triangle \mathrm{E} 9$ ); the $\triangle \mathrm{E} 9$ mutations have been reported to cause early onset familial $\mathrm{AD}^{1-5}$. We used Transcription Activator-Like Effector Nuclease (TALEN) to delete the 3' splice site of exon 9 in the marmoset PSEN1 gene; to this end, TALEN exhibits high genome-editing efficacy, generates few off-target effects, and produces minimal mosaicism. Indeed, whole genome sequencing and other analyses illustrated an inclusive absence of off-target effects and apparent absence of mosaicism. Fibroblasts obtained from newborns indicated occurrence of full-length presenilin 1 protein (PS1) caused by perturbation of PS1 endoproteolysis as well as an increased ratio of $A \beta_{42} / A \beta_{40}$ production, a signature of familial $\mathrm{AD}$ pathogenesis. To our knowledge, this is the first non-human primate model of familial AD. The model lines will be made available to the research community to facilitate the global fight against AD. 


\section{Introduction}

$\mathrm{AD}$ is the most common neurodegenerative disease that deprives patients and their families of human dignity. The number of individuals with dementia in the world was approximately 50 million in $2019^{6}$, and $\mathrm{AD}$ accounted for $50-70 \%$ of all these cases ${ }^{7}$. Clinically, $\mathrm{AD}$ is characterized by early memory deficits followed by a decline in other cognitive functions ${ }^{7,8}$. The pathological changes associated with AD development precede the clinical manifestation by approximately 20 years ${ }^{9}$ and comprise the following: deposition of amyloid $\beta$ peptide $(\mathrm{A} \beta)$ as extracellular plaques, accumulation of hyperphosphorylated tau as intracellular neurofibrillary tangles (NFTs) and chronic neuroinflammation followed by neurodegeneration mainly in the cerebral cortex and hippocampus ${ }^{10,11}$. The genetic and pathological observations collectively support the $A \beta$ hypothesis depicting that $A \beta$ plays a central role in the $\mathrm{AD}$ pathogenesis ${ }^{12}$. Mouse $\mathrm{AD}$ models appear to have reached a highly advanced state of development by overcoming overexpression artefacts in recent times ${ }^{13-17}$. The amyloid precursor protein (App) knock-in mice that harbor familial AD mutations with the $\mathrm{A} \beta$ sequence humanized ${ }^{13}$ reproduced $A \beta$ pathology and neuroinflammation without overexpression of APP. These mice exhibited cognitive dysfunctions as analyzed by Intellicage ${ }^{18}$ presumably through vasoconstriction by pericytes $^{19}$, impairment of grid cells ${ }^{16}$ and plaque-induced gene network ${ }^{17}$, providing the mechanistic insights into the action of $\mathrm{A} \beta$ pathology.

These model mice however never exhibited tau pathology or neurodegeneration even when crossbred with human MAPT knock-in mice, in which the entire Mapt gene had been humanized ${ }^{15,20}$. The reason for the absence of tauopathy and neurodegeneration in these models remains elusive, but this may simply be because mice live only as long as approximately two years whereas the entire pathological changes in human brain proceed over decades ${ }^{9}$. The discrepancy between mice and humans may also be accounted for by the species differences in genetics, neuroanatomy, immunity and metabolism. In addition, various higher cognitive functions specific to primates, represented by the presence of highly developed prefrontal $\operatorname{cortex}^{21}$, are affected in AD. In this respect, outcomes from mouse models are more suitable for application to preclinical studies than directly to clinical studies. We thus came to the conclusion that a non-human primate model is needed for "near"-clinical studies $^{22-24}$. The developmental engineering of primates is, however, much more challenging than that of rodents; thus far we have created three mutant primates using 810 oocytes as described below.

Common marmosets (marmosets, Callithrix jacchus) are small non-human primates that belong to the New World Primates. They have been increasingly utilized in neuroscience because of advantages that arose over other research primates ${ }^{22}$ (Supplementary Table 1). Marmosets possess genetic backgrounds, physiological functions, brain structures and complex cognitive/social behaviors similar to those of humans; they communicate mainly via visual and auditory measures. In association with $\mathrm{AD}$ research, the amino acid sequence of $\mathrm{A} \beta$ is identical to that of humans, and the aged wildtype marmosets start accumulating $A \beta$ from 7 years old or even earlier ${ }^{25,26}$. In addition, adolescent 
marmosets exhibit tau hyperphosphorylatiton, but not NFT formation, in brain that increases with aging $^{26}$. Their life spans in captivity are as long as 10 to 15 years, making them suitable for aging research $^{27}$. Their immune systems and metabolic functions resemble those of humans ${ }^{27,28}$ and thus may affect the pathogenic processes related to $\mathrm{AD}^{29-31}$. Because sleep disorder is an early clinical incident in $\mathrm{AD}^{32}$, it is noteworthy that marmosets share with humans the sleep phases composed of rapid eye movement (REM) and non-REM cycles ${ }^{33}$. Among various non-human primate species, the marmoset seems most applicable to genetic manipulation, i.e. generation of designed mutants, for which the high reproductive efficacy is advantageous ${ }^{22,34}$. Furthermore, fecundity characteristics of marmosets, such as the short period of sexual maturity, multiple birth, short gestation interval, are suitable to produce genetically modified disease models. We decided to introduce a pathogenic mutation in the marmoset PSEN1 gene because the majority of familial AD-causing mutations reside in the PSEN1 gene ${ }^{35}$. Typically, deletion mutations in exon $9^{1-5}$ or point mutations at the 3 ' splice site (acceptor site) of exon 9 in the PSEN1 gene cause dominantly inherited familial AD. The point mutations instigate exon 9 elimination and S290C modification in the corresponding mRNA at the junction sites of exons 8 and 10 via conversion of alternative splicing ${ }^{36-40}$. We thus set out to generate a marmoset model of AD in which the exon 9 of PSENI gene product is deleted using TALEN to produce $\mathrm{AD}$ marmoset models because TALEN exhibits high genome-editing efficacy and because TALEN generates few off-target effects and produces little mosaicism ${ }^{34,41}$. To our knowledge, this is the first case, in which TALEN has successfully been applied to artificial exon skipping in non-human primates.

\section{Results}

\section{Evaluation of TALEN activity}

We used the Platinum TALENs designed to target 3' splice site of exon 9 of the marmoset PSEN1 gene (Figure 1a ${ }^{42,43}$. After introduction of the TALEN mRNAs into the nucleus of marmoset pronuclear stage embryos, we performed surveyor assays and sequencing with the genomic DNA extracted from the developed embryos. We found that 2 out of 3 embryos exhibited deletions at the target sequences including the acceptor site as expected (Figure 1b). To confirm exclusion of exon 9 in the PSEN1 mRNA, we performed RT-PCR and sequenced the corresponding cDNA sequencing using RNAs extracted form 4-cell-stage or single blastomeres of the TALEN-injected marmoset embryos (Figure 1c $)^{34}$. We consequently verified complete exclusion of exon 9 in two out of two 4-cell-stage embryos and 2 out of 5 single blastomere, and 3 were failed to amplify the cDNA (Figure 1d). This indicated that the 3' splice site-deletion resulted in exclusion of exon 9 of the mRNA transcribed from the PSEN1 gene. There was no wild-type sequence in the embryos or single blastomeres in which 3' splice site was destroyed, suggesting that the mutations took place in a biallelic manner. We later noted that homozygous deletion of PSEN1 exon 9 appear to cause embryonic lethality in vivo (see the following). 


\section{Generation of marmosets lacking PSEN1 exon 9 in the corresponding mRNA (PSEN1- $\triangle E 9)$ and apparent absence of mosaicism}

The embryos treated with TALEN were transferred into uterus of surrogate mother marmosets to generate PSEN1 exon9 deleted AD model marmosets. However, the developmental rate of the embryos (35\%) was significantly lower than that in our previous study ${ }^{34}$, and no pregnant animals were obtained even after 40 zygotic injections. These results implied that the deletion mutations of the PSEN1-AE9 in the biallelic status are likely to cause the low embryonic developmental rate and embryonic lethality presumably due to the disruption of Notch signaling ${ }^{44}$. This was somewhat expected because mice deficient in $\mathrm{PS}^{45,46}$ or lacking the active site aspartate ${ }^{47}$ exhibited embryonic lethality and because the protein domain corresponding to PSEN1 exon 9 is a site for endoproteolysis ${ }^{48}$, which is perturbed by the active site destruction ${ }^{47}$. We thus came to realize that we need to introduce the $\Delta \mathrm{E} 9$ mutations in a monoallelic manner.

To avoid the biallelism of the PSEN1 gene mutations, we injected TALEN mRNAs into 810 ova and then performed in vitro fertilization on the 578 (71.4\%) ova that survived, using wild-type marmoset sperms. After the in vitro fertilization, 218 (37.7\%) zygotes were obtained then transferred 154 (70.6\%) embryos that developed to above 6-cell stage into uterus of 77 surrogate mothers. Around the 145th day from the ovulation of the surrogate mother, we obtained 6 marmoset neonates by normal delivery or by Caesarean section (Figure 2a, Table 1).

Surveyor assays of the genomic DNA isolated from hair roots of the newborns suggested that 3 out of 6 neonates carried PSEN1 gene mutations. Sequence analyses of the subcloned PCR products from the genome DNA indicated that 3 different patterns of the PSEN1 gene mutations in these animals. 2 animals carried 6-bp deletions and another newborn harbored 9-bp deletions at the 3' splicing site, envisaging deletion of the region in mRNA that corresponded to the genomic PSEN1 exon 9 (Figure 2b). The numbers of wild-type and truncated genes in the subclones collected from the mutants' hair roots were 53 and 47 out of 100 in I774gmF, 51 and 49 in I943gmM, and 59 and 41 in I949gmM, respectively (Figure 2c): approximately 50\% of the clones carried the identical mutations in each case. Consistently, RT-PCR followed by sequencing of cDNA verified the excision of exon 9 in the mRNAs extracted from hair root samples of the mutants. These observations suggest two possibilities: [1] a presence of heterozygous mutations essentially in all the cells; [2] a presence of wild-type and homozygous mutant cells in a 1:1 ratio, i.e., mosaicism. The second possibility can be ruled out because homozygous $P S E N 1-\triangle \mathrm{E} 9$ mutations result in embryonic lethality presumably via a Notch phenotype ${ }^{5,46} 49$ that would preclude half of the neural stem cells from differentiating to neurons during development. It is noteworthy that $\gamma$-secretase cleaves the truncated Notch in a cellautonomous manner ${ }^{50}$. These results and speculations indicate a probable absence of mosaicism in the mutant marmosets ${ }^{34}$. Consistently, single cell PCR analyses indicated that two of the mutants, 
I774gmF and $1949 \mathrm{gmM}$, were mosaicism-free: ten out of ten single cells showed heterozygous mutations. However, the other mutant, $1943 \mathrm{gmM}$, exhibited an extensive mosaicism (>80\%) and was thus excluded from further analyses (Supplementary Figure 1). The sequence analyses of the cDNAs also showed that there were no insertions or deletions in the exons 8 and 10 in the PSEN1 gene (Figure 2d, Supplementary Figure 2). We thus concluded that we successfully acquired PSENI- $\triangle \mathrm{E} 9$ marmoset neonates.

\section{Off-target analyses of the mutant PSEN1- $\triangle \mathrm{E} 9$ marmosets}

A number of genome editing-based studies suffer form off-target effects ${ }^{41}$. We analyzed the off-target mutations in the mutant PSEN1- $\triangle \mathrm{E} 9$ marmosets in two ways. The online Paired Target Finder tool was used to search for candidate off-target sites ${ }^{34}$ for calculation an average score at each potential off-target site obtained from the search and identified the top 10 candidate sites (Supplementary Table 2). Genomic DNA extracted from hair roots of PSEN1- $\mathrm{E} 9$ marmosets was subjected to PCR then determined the sequence by direct sequencing. None of the PSEN1- $\triangle \mathrm{E} 9$ marmosets exhibited any mutations in the off-target candidate sites. Second, we performed whole genome sequencing (WGS) of the genomic DNA obtained from the first PSEN1- $\triangle \mathrm{E} 9$ marmoset (I774gmF) and from her parents at the average coverage over genome of $42.1,57.4$, and $62.2 \mathrm{x}$ for the neonate, father, and mother, respectively (Supplementary Table 3). In order to process the WGS data sets, we performed Illumina Dynamic Read Analysis for GENomics (DRAGEN) pipeline (version 3.5.7) ${ }^{51}$ for mapping and variant calling process at a default parameter with "CJA1912RKC" marmoset genome reference sequence (GCA_013373975.1). We used this highly permissive parameter in variant calling and did not filter out variants to keep as many variants in off-target candidate sites as possible. By comparing all the variants from the PSEN1- $\triangle \mathrm{E} 9$ marmoset (I774gmF) with those from her parents, we found 306,492 variants only in the PSENI- $\triangle \mathrm{E} 9$ marmoset (I774gmF) (Supplementary Figure 3). None of the 306,492 variants were present within the 10 off-target candidate sites. These analyses further confirmed the absence of the off-target mutations. We thus declare that application of the TALEN technology to generation of the PSENI- $\mathrm{E} 9$ marmosets has fully succeeded.

\section{Endoproteolysis of the mutant marmoset-derived PS1 and secretion of $A \beta_{42}$ versus $A \beta_{40}$}

PS1 serves as a major catalytic subunit for the $\gamma$-secretase complex that generates A $\beta$ from the $C$ terminal fragment of APP after the limited proteolysis by $\beta$-secretase ${ }^{45,47,48,52}$. Most, if not all, of the pathogenic mutations found in the PSEN1 gene cause familial AD by elevating the ratio of $A \beta_{42} / A \beta_{40}$ production $^{53-56}$. The ratio matters because Kim et al. demonstrated that $A \beta_{42}$ is causal whereas $A \beta_{40}$ is protective in the pathological processes ${ }^{57}$. To biochemically analyze the mutant marmosets in the least invasive manner, we established primary fibroblasts from the wild-type and mutant marmosets edge of the ear lobe. We first examined the effect of exon 9 deletion on the endoproteolytic status of PS1 
protein because such deletion impacts on the global PS1 endopeptidase activity ${ }^{5}$. We performed Western blot analysis of fibroblasts derived from wild-type and PSEN1- $\triangle \mathrm{E} 9$ marmosets using a set of antibodies that recognize the $\mathrm{N}$ - and C-termini of PS1. The exon 9 deficiency in the two independent mutants, i.e. I774gmF and I1943gmM, gave rise to a full-length PS1 that was absent in the wild-type fibroblasts (Fig. 3a). Consistently, the quantities of the N-terminal and C-terminal fragments in the mutants were reduced to approximately half the levels compared to those in wild-type cells. These observations indicate that the monoallelic exon 9 deletion caused perturbation of the PS1 endoproteolysis in a heterozygous manner and that the nature of endoproteolysis was autolytic. The deletion also induced an amino acid sequence conversion, S290C, as shown in Supplementary Figure $2^{40}$.

We then quantified $A \beta_{42}$ and $A \beta_{40}$ secreted from the wild-type and mutant fibroblasts by enzyme-linked immunosorbent assay (ELISA) for the reasons stated above. The quantity of $A \beta_{42}$ was significantly increased in the mutant-derived media while that of $A \beta_{40}$ also showed a significant reduction. Consequently, the ratio of $A \beta_{42} / A \beta_{40}$ production was statistically significantly increased approximately 3-fold (Fig. 3b), a hallmark of familial AD pathogenesis. Similar results had been reported using cultured human fibroblasts and lymphocytes obtained from PSEN1 mutation carries ${ }^{53-}$ ${ }^{56} . \mathrm{A} \beta_{43}{ }^{58}$ was undetectable. These observations indicate that the PSENI- $\triangle \mathrm{E} 9$ mutations introduced into the marmosets are indeed pathogenic.

\section{Discussion}

Steiner et al. previously demonstrated that a PSEN1- $\triangle \mathrm{E} 9$ mutation exerted its pathogenic effect via an amino acid conversion, S290C, rather than perturbed PS1 endoproteolysis ${ }^{40}$. This effect of the amino acid conversion on the $A \beta_{42} / A \beta_{40}$ ratio is also likely to apply to our observation in the fibroblasts obtained from the mutant marmosets because they also carry the S290C conversion (Supplementary Figure 2). There is however a distinct difference between the studies by Steiner $e t$ al. and by us. Steiner et al. used a cDNA overexpression paradigm in cultured cells and in Caenorhabditis elegans. This approach does not necessarily warrant the stoichiometric formation of $\gamma$-secretase complex ${ }^{52}$ and is comparable to homozygous deletion of exon 9 in vivo, which resulted in embryonic lethality (see Generation of marmosets lacking PSEN1 exon 9 in the corresponding mRNA (PSEN1- $\triangle E 9)$ and apparent absence of mosaicism). In addition, the results shown by Steiner et al. do not exclude the possible need for simultaneous presence of exon 9 deletion and S290C mutation together to evoke the pathogenic activity in a coordinated manner, and the S290C mutation by itself is unlikely to account for the symptom of spastic paraparesis often observed in PSENI- $\triangle \mathrm{E} 9$ patients ${ }^{1}$. The embryonic lethality caused by the biallelic presence of PSEN1- $\triangle \mathrm{E} 9$ mutations also interrogates the pathogenic role of the S290C mutation by itself because most pathogenic point mutations in Psen 1 gene generally resulted in non-lethal phenotypes in a homozygous status at least in mice except for a few cases ${ }^{58,59}$. 
We thus cannot rule out the possible role of $\Delta \mathrm{E} 9$ mutations alone in the pathogenicity in vivo. These issues would be better addressed if we could create various mutant knock-in mice, but deletion of Psenl exon 9 in mice generated a termination codon within the Psenl-coding sequences (Kaori Sato and Nagata, unpublished observations), rendering such attempts difficult. These queries thus remain as open questions, but they are beyond the scope of our present study the aim of which is to establish a non-human primate model of familial AD.

Currently, the CRISPR/Cas9 technology including Base Editor (BE) appears the prevalent method for genome editing in general. Indeed, Wang et al. succeeded in generating a HutchinsonGilford progeria syndrome cynomolgus monkey model using $\mathrm{BE}^{60}$. In the present study, we used a slightly different technique, TALEN, because it is highly efficient, and produces less mosaicism ${ }^{34}$. Further, application of BE to genome editing of the marmoset PSEN1 gene has proven more challenging than expected (Kumita et al., unpublished observations). Consistently, the genome editing efficacy in the present study by TALEN was as high as 50\%. This study showed that targeting 3' splice site of the PSEN1 gene induced whole exon 9 skipping by TALEN and cDNA sequence analyses showed that neither insert nor deletion occurred at exon 8 or exson10 in the PSEN1 gene. The strategy used in this study, induce mutation at the splice site of the target gene, is a new method for precisely deletion whole target exon at the target gene, without any mutation at neighbor exon. Therefore, destruction of the splice site in the PSEN1 gene to induce the exon 9 skipping by this specific genomeediting tool appears the most realistic approach to generate a non-human primate model of familial AD. The oldest mutant marmoset among the three mutants, I774gmF, was born in April of 2019 thus needs some more time to become reproductive at present, making it difficult to provide direct evidence for the germ line transmission of the pathogenic mutations. However, we presume that the apparent lack of mosaicism (see Results) implies the presence of the mutations in the reproductive cells because a similar approach to generate IL2RG knock-out marmosets using TALEN resulted in 100\% germ line transmission ${ }^{34}$.

To our knowledge, this is the first non-human primate model of familial AD ever produced. Because the wild-type marmosets start accumulating $A \beta$ in brain around the age of 7 or even earlier ${ }^{25}$, because the age-of-onset of PSEN1- $\triangle \mathrm{E} 9$ humans varies in their 40 's ${ }^{12}{ }^{39}$, and because $\mathrm{A} \beta$ deposition arises approximately two decades prior to the disease on-set in humans ${ }^{9}$, we anticipate the mutant marmosets to start exhibiting $A \beta$ pathology from 2-3 years old. Relevance of the mechanistic findings obtained using the model mice ${ }^{16,17,19}$ shall be confirmed if the mutant marmosets are utilized. Because the marmosets live much longer than mice, they may develop tau pathology and neurodegeneration, which model mice failed to recapitulate. If so, they would become convenient tools to establish the cause-and-effect relationship and to elucidate the mechanisms by which $\mathrm{A} \beta$ amyloidosis evokes tau pathology and neurodegeneration. They would first become applicable to primary basic studies being used for humans, including non-invasive imaging analyses by MRI to determine morphometric 
changes and by positron emission tomography (PET) to search for $\mathrm{A} \beta$ and tau pathology. The body fluids such as blood and cerebrospinal fluid may be collected to identify biomarkers. In a more clinical sense, we can subject them to highly sensitive cognitive analyses such as touch-sensitive technology ${ }^{61}$ or can analyze the sleep disturbances ${ }^{33}$. We can also examine the default mode network, the changes of which represent an early sign of preclinical AD, by functional MRI ${ }^{62,63}$. Model mice are incompetent for these studies. In addition, the effect of $A \beta$ pathology on the function of prefrontal cortex ${ }^{21}$ can be understood only by analyzing the mutant marmosets. For pharmaceutical studies, the mouse model can first be used for initial screening, and the marmoset model can then be used for the second screening before clinical trials. They would also become tools to examine the anti-tau pathology and anti-neurodegeneration medication candidates if these pathological features arise. We are making maximum efforts to expand our colonies so that the marmoset model can be shared by the global research community in the near future. 


\section{Methods}

\section{Animals}

All animal experiments were carried out in accordance with guidelines for animal experimentation from the RIKEN Center for Brain Science and the Central Institute for Experimental Animals (CIEA: 18031A, 19033A). The CIEA standard guidelines are in accordance with the guidelines for the proper conduct of animal experiments determined by the Science Council of Japan. The marmosets used in this study were purchased from CLEA Japan, Inc., Tokyo, Japan. The animals ranged from 2-4.5 yearsold with body weights between 300 and $450 \mathrm{~g}$.

\section{In vitro transcription of TALEN mRNA}

We employed a two-step Golden Gate assembly method using the Platinum Gate TALEN Kit (Addgene; cat\#1000000043) to construct Platinum TALEN plasmids containing the homodimer-type FokI nuclease domain. The assembled repeat arrays were subsequently inserted into the final destination vector, ptCMV-153/47-VR. TALEN mRNA was synthesized using the mMESSAGE mMACHINE T7 Ultra Transcription Kit (Thermo Fisher Scientific, AM1345). Transcribed mRNA was purified using the MEGAclear Transcription Clean-Up Kit (Thermo Fisher Scientific, AM1908), and Nuclease-Free water (Thermo Fisher Scientific, AM9937) was used for the elution step and subsequent dilution. For microinjection, an aqueous solution was used in which left TALEN and right TALEN mRNAs were mixed in equal amounts so that the final concentration was $8 \mathrm{ng} / \mu \mathrm{l}$.

\section{Procedures for oocytes collection and in vitro fertilization}

Oocyte collection and in vitro fertilization (IVF) was performed as previously described ${ }^{22,64}$. Briefly, 62 female marmosets whose plasma progesterone levels under $10 \mathrm{ng} / \mathrm{ml}$ were used for the follicular stimulation. To collect the oocytes, the selected marmosets were intramuscularly treated with Purified Human Menopausal Gonadotrophin, follicle-stimulating hormone (hFSH, 25IU; FOLYRMON-P injection, Fuji Pharma) for five times every other day. The day after the last hFSH administration, human chorionic gonadotropin (hCG, 75IU; Gonatropin, ASKA Pharmaceutical) was subsequently administered by an intramuscular injection. The hormone-treated female marmosets were preanesthetized with $0.04 \mathrm{mg} / \mathrm{kg}$ medetomidine (Domitor; Nippon Zenyaku Kogyo), $0.40 \mathrm{mg} / \mathrm{kg}$ midazolam (Dormicam; Astellas Pharma) and $0.40 \mathrm{mg} / \mathrm{kg}$ butorphanol (Vetorphale; Meiji Seika Pharma). The ovum pickup was performed at 17-20 hours after the hCG injection. During the operation, the marmosets were anesthetized by isoflurane (Isoflurane Inhalation Solution; Pfizer) inhalation. The collected ova were incubated in Porcine Oocyte Medium (Research Institute for the Functional Peptides, IFP1010P) for 28-32 hours for in vitro maturation ${ }^{65}$. For IVF, semen was collected from healthy male marmosets and diluted to $3.6 \times 10^{6} \mathrm{sperm} / \mathrm{ml}$, after washing with TYH medium (LSI Medience, DR01031). Insemination was performed via the co-incubation of $3.6 \times 10^{4}$ sperm per oocyte for $10-16$ hours at $37^{\circ} \mathrm{C}$ with $5 \% \mathrm{CO}_{2}, 5 \% \mathrm{O}_{2}$, and $90 \% \mathrm{~N}_{2}$.

\section{Blastomere splitting}


TALEN-mRNA-injected embryos that had reached the 4-cell stage and above were directed to blastomere splitting as previously described ${ }^{34}$. Briefly, the embryo specimens were treated with acidified Tyrode's solution (Origio, 10605000) to lyse the zona pellucida. Naked embryos were transferred into Embryo Biopsy Medium (Origio, 10620010). After several minutes, embryos that exhibited weak adhesion between blastomeres were split into single blastomeres using glass capillaries and washed in phosphate-buffered saline (PBS) (-) drops immediately. The blastomere was transferred to a test tube with a small amount of PBS and used for subsequent analyses.

\section{Embryo transfer}

The embryos that grown to 6-cell-stage or higher were transferred to the uteri of surrogate mothers as previously described ${ }^{22,64}$. The method for obtaining newborns was based on natural delivery, but if delivery was judged to be difficult, a Caesarean section was performed on day 145 after embryo transfer ${ }^{34}$.

\section{PCR for genotyping}

Genomic DNA was extracted from marmoset cord blood and hair roots using QIAamp DNA Micro Kit (Qiagen, 56304) according to the manufacturer's instructions. Embryos and blastomeres were used as templates without any genome extraction processing. PCR was performed using specific primers followed by subsequent sequencing or surveyor assay (Supplementary Table 4). Each PCR mixture contained 1X PCR buffer, $0.2 \mathrm{mM}$ of dNTPs, $0.5 \mathrm{mM}$ of each primer, $20 \mathrm{ng}$ of template DNA and 2.5 $\mathrm{U}$ of KOD-Plus-Neo (Toyobo, KOD-401) in a total volume of $20 \mu \mathrm{l}$. PCR was performed using the following PCR cycling conditions: 1st PCR (for embryo and blastomere), one cycle of $94^{\circ} \mathrm{C}$ for $2 \mathrm{~min}$, $45 \mathrm{cycles}$ of $98^{\circ} \mathrm{C}$ for $10 \mathrm{sec}, 60^{\circ} \mathrm{C}$ for $10 \mathrm{sec}$ and $68^{\circ} \mathrm{C}$ for $40 \mathrm{sec}$, one cycle of $68^{\circ} \mathrm{C}$ for $7 \mathrm{~min} .2 \mathrm{nd}$ PCR (for all samples), one cycle of $94^{\circ} \mathrm{C}$ for $2 \mathrm{~min}, 35$ cycles of $98^{\circ} \mathrm{C}$ for $10 \mathrm{sec}, 60^{\circ} \mathrm{C}$ for $10 \mathrm{sec}$ and $68^{\circ} \mathrm{C}$ for $30 \mathrm{sec}$, one cycle of $68^{\circ} \mathrm{C}$ for $7 \mathrm{~min}$.

\section{Sequencing analyses}

To confirm the sequences of the TALEN target sites, PCR products were subcloned into the Zero Blunt PCR Cloning Kit (Thermo fisher scientific, 44-0302) according to manufacturer's instructions. The plasmids obtained were transfomed with ECOS Competent E. coli DH5 $\alpha$ (Nippon gene, 316-06233) and cultured on LB agar containing Kanamycin. After amplifying the plasmid using the emerged single colony, it was reacted using M13 primer and Big Dye terminator v3.1 cycle sequence kit (Thermo fisher scientific, 4337455), and gene sequences were analyzed by 3130 Genetic Analyzer (Thermo fisher scientific).

\section{Surveyor assay}

The SURVEYOR mutation detection kit (IDT, 706025), one of the mutation analysis methods that identifies mismatches in double-strand DNA, was used to detect genetic modifications at the TALEN target site. Briefly, $8 \mu 1$ of the PCR product described above. For the analysis of biallelic mutations in the PSENI gene, a sample in which $4 \mu 1$ of the PCR product was mixed with an equal amount of the 
PCR product prepared using wild-type PSEN1 as a template was also prepared. The sample digested with Nuclease was electrophoresed on Novex TBE Gels, 10\%, 12 well (Thermo fisher scientific, EC62752BOX) and then subjected to nucleic acid staining with GelRed (Fujifilm Wako Chemicals, 518-24031).

\section{Single-cell PCR}

To establish the marmoset primary fibroblast cells, approximately $3 \mathrm{~mm}^{3}$ was excised from the edge of the earlobe of marmosets. Tissue from each animal was cultured at $37{ }^{\circ} \mathrm{C}$ and $5 \% \mathrm{CO}_{2}$ with Dulbecco's modified Eagle's medium + GlutaMAX (Thermo Fisher Scientific, 10566-024) containing 10\% FBS (Biowest) and a penicillin-streptomycin cocktail (Thermo Fisher Scientific, 15240-062). Cultured fibroblast cells were harvested and washed in PBS (-) following which single cells were isolated one by one with a glass capillary tube and placed into individual sampling tubes. Direct PCR and sequencing were then performed, with the PCR conditions used being the same as those used for the genotyping PCR. The electrophoresis of PCR products was performed with 10\%TBE Gels (Thermo Fisher, EC62752BOX), followed by nucleic acid staining with GelRed.

\section{RT-PCR}

Total RNA was extracted from marmoset embryos, blastomeres, and hair roots using Nucleospin RNA plus XS (Takara, U0990B) according to the manufacturer's instructions. cDNA was synthesized using ReverTra Ace - $\alpha$ - (Toyobo, FSK-101F). In the reaction, the sample was divided into two: one received Reverse Transcriptase, and the other received the same amount of water as a control to evaluate genomic DNA contamination. PCR was performed the primers designed on exons (Supplementary Table 4). Each PCR mixture contained 1X PCR buffer, $0.2 \mathrm{mM}$ of dNTPs, $0.5 \mathrm{mM}$ of each primer, $20 \mathrm{ng}$ of template DNA and $2.5 \mathrm{U}$ of KOD-Plus-Neo (Toyobo, KOD-401) in a total volume of $20 \mu \mathrm{l}$. PCR was performed using the following PCR cycling conditions: 1st PCR (for embryo and blastomere): one cycle of $94^{\circ} \mathrm{C}$ for $2 \mathrm{~min}, 45$ cycles of $98^{\circ} \mathrm{C}$ for $10 \mathrm{sec}, 60^{\circ} \mathrm{C}$ for $10 \mathrm{sec}$ and $68^{\circ} \mathrm{C}$ for $40 \mathrm{sec}$, and one cycle of $68^{\circ} \mathrm{C}$ for $7 \mathrm{~min} .2 \mathrm{nd} \mathrm{PCR}$ (for all samples): one cycle of $94^{\circ} \mathrm{C}$ for $2 \mathrm{~min}, 35 \mathrm{cycles}$ of $98^{\circ} \mathrm{C}$ for $10 \mathrm{sec}, 60^{\circ} \mathrm{C}$ for $10 \mathrm{sec}$ and $68^{\circ} \mathrm{C}$ for $30 \mathrm{sec}$, one cycle of $68^{\circ} \mathrm{C}$ for 7 $\min$.

\section{Whole-genome sequencing (WGS)}

To prepare the genomic DNA for WGS, the edge of the ear lobe (approximately $3 \mathrm{~mm}$ square) was cut out from the marmosets as a lowly invasive body tissue collection. Genomic DNA extraction from the ear tissue was performed using the QIAamp Micro DNA kit (Qiagen, 56304), according to the manufacturer's instructions. Briefly, the tissue was incubated in lysis buffer and Proteinase K overnight at $56^{\circ} \mathrm{C}$, then genomic DNA was collected by column purification with low-TE (Tris-Hcl $10 \mathrm{mM}$, EDTA $0.1 \mathrm{mM}$, ph8.0) elution. Whole genome sequencing was performed using Illumina NovaSeq. FASTQ files for all WGS runs are deposited under accession number DRR239155, DRR239156, DRR239157 in DNA Data Bank of Japan (DDBJ) Sequence Read Archive (DRA). For processing the 
WGS data sets, Illumina DRAGEN pipeline (version 3.5.7) was performed for mapping and variant calling process at a default parameter with "CJA1912RKC" marmoset genome reference sequence (GCA_013373975.1) (Supplementary Table 3). We used this highly permissive parameter in variant calling and did not filter out variants to keep as many variants in off-target regions as possible. By comparing all the variants from the mutant PSENI (I774gmF) marmoset with those from her parents, 306,492 variants were found only in the mutant PSEN1 marmoset without any filtering.

\section{Off-target analysis by Paired Target Finder Tool}

Paired Target Finder (https://tale-nt.cac.cornell.edu/node/add/talef-off-paired) was used to search for potential off-target sites $^{66}$. As the reference, CJA1912RKC (GenBank assembly accession: GCA_013373975.1), which is the whole genome sequence of marmoset, was set in the search database, and the RVD sequence of TALEN was provided as follows; RVD Sequence 1, NI HD HD NG NN NN NI NI NG NG NG NG NN NG HD NG NG; RVD Sequence 2, NI NG NG HD NI HD HD NI NI HD HD NI NG NI HD HD NI. The minimum and maximum lengths of the spacers were set to 10 and 30 , respectively. Other parameters were set as recommended. Genomic DNA extracted from marmoset hair roots using QIAamp DNA Micro Kit (Qiagen, 56304) was subjected to PCR with specific primers followed by direct sequencing (Supplementary Table 5). Each PCR mixture contained 1X KOD One PCR Master Mix (Toyobo, KMM-101), $0.5 \mathrm{mM}$ of each primer and $10 \mathrm{ng}$ of template DNA in a total volume of $20 \mu$ l. PCR was performed using the following PCR cycling conditions: 30 cycles of $98^{\circ} \mathrm{C}$ for $10 \mathrm{sec}, 60^{\circ} \mathrm{C}$ for $5 \mathrm{sec}$ and $68^{\circ} \mathrm{C}$ for $1 \mathrm{sec}$. The amplicon was purified using NucleoSpin Gel and PCR Clean-up (Takara Bio, 740609), and reacted with one of the PCR primer and Big Dye terminator v3.1 cycle sequence kit (Thermo fisher scientific, 4337455), and the gene sequence was identified by 3130 Genetic Analyzer (Thermo fisher scientific).

\section{Western blot analysis}

We established primary fibroblast lines from ear skin tissues of the wild-type and PSEN1- $\mathrm{E} 9$ marmosets, i.e. I774gmF and $1943 \mathrm{gmM}$. We performed Western blotting as previously described ${ }^{67}$. Briefly, cells were lysed and subjected to subcellular fractionation using ProteoExtract Subcellular Proteome Extraction Kit (Merck, \#539790) according to the manufacturer's instructions. We loaded the membrane fractions onto polyacrylamide gels, electrophoresed them, blotted them onto PVDF membranes (Merck Millipore), which were then treated with the ECL Prime blocking agent (GE Healthcare) and incubated with the primary antibodies raised against the PS1 N-terminal (G1Nr5) and C-terminal (G1L3) domains ${ }^{68} 69$. We used an antibody to sodium-potassium ATPase (EP1845Y, Abcam, ab76020) as a loading control of the membrane fraction.

\section{Enzyme-linked immunosorbent assay (ELISA)}

$A \beta_{40}$ and $A \beta_{42}$ was quantified using ELISA as previously described ${ }^{59}$. Briefly, culture media, collected from the primary skin fibroblasts at 72 hours after incubation, were mixed with 11 times the volume of $6 \mathrm{M}$ guanidine- $\mathrm{HCl}$. We then quantified $\mathrm{A} \beta_{40}$ and $\mathrm{A} \beta_{42}$ using $\mathrm{A} \beta$ ELISA kit (Wako, 294-62501 and 
294-62601), according to the manufacturer's instructions. Quantification of $A \beta_{43}$ was performed as previously described ${ }^{58}$.

\section{Statistic analysis}

All data are shown as the mean \pm s.e.m. For comparison between two groups, data were analyzed by Student's t-test. All the data were collected and processed in a randomized and blinded manner.

\section{Author Contributions}

H.S., K.N., and T.C.S. made a primary design of the AD model. T.S. and T.Y. created TALENs. K.S., W.K. and E.S. planned developmental engineering procedures. K.S., W.K., T.I., Y.K. and E.S. generated mutant marmosets and fibroblasts thereof, and performed molecular biological analyses. H.S. and N.M. performed biochemical experiments. K.S. (Kaori Sato), and K.N. performed mouse experiments. M.T., R.M., K.O., and Y.O. analyzed the WGS data. K.S., H.S., W.K., K.N., T.S., T.Y., T.C.S. and E.S. jointly analyzed and interpreted the other data. K.S., H.S., W.K., K.N., T.S., T.Y., M.T., R.M., K.O., Y.O., T.C.S. and E.S. wrote and edited the manuscript.

\section{Acknowledgements}

We thank Taisuke Tomita, University of Tokyo, for providing the antibodies to PS1. We thank Yukiko Nagai, RIKEN CBS, for secretarial assistance. We thank Yuko Yamada, Tomoko Ishibuchi, Mitsuyoshi Togashi, Yoshihisa Sawada and members of Center of Basic Technology in Marmoset, Central Institute for Experimental Animals, for technical assistance for producing and maintaining the AD models. We also thank Takayuki Mineshige and Terumi Yurimoto, Central Institute for Experimental Animals, for veterinarian managements. This work was supported by AMED under Grant Number JP20dm0207001 (Brain Mapping by Integrated Neurotechnologies for Disease Studies (Brain/MINDS)) (T.C.S.) and JP20dm0207065 (Study of developing neurodegenerative model marmosets and establishment of novel reproductive methodology) (E.S).

\section{Conflicts of interest}

The authors declare no conflicts of interest in the present study. 


\section{Figure 1.}

a)

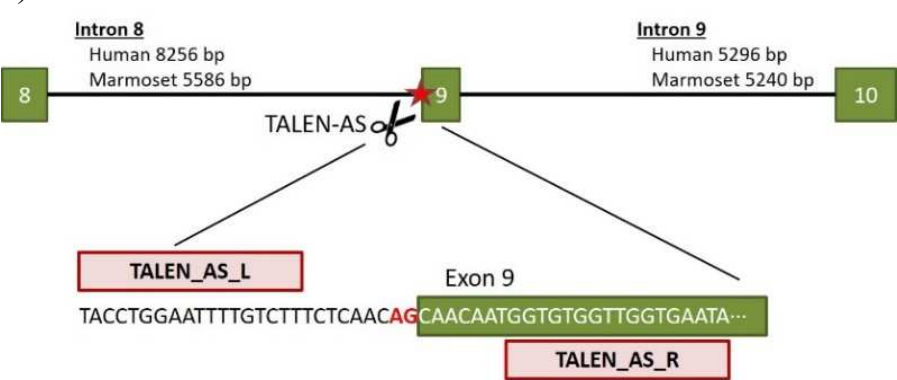

b)

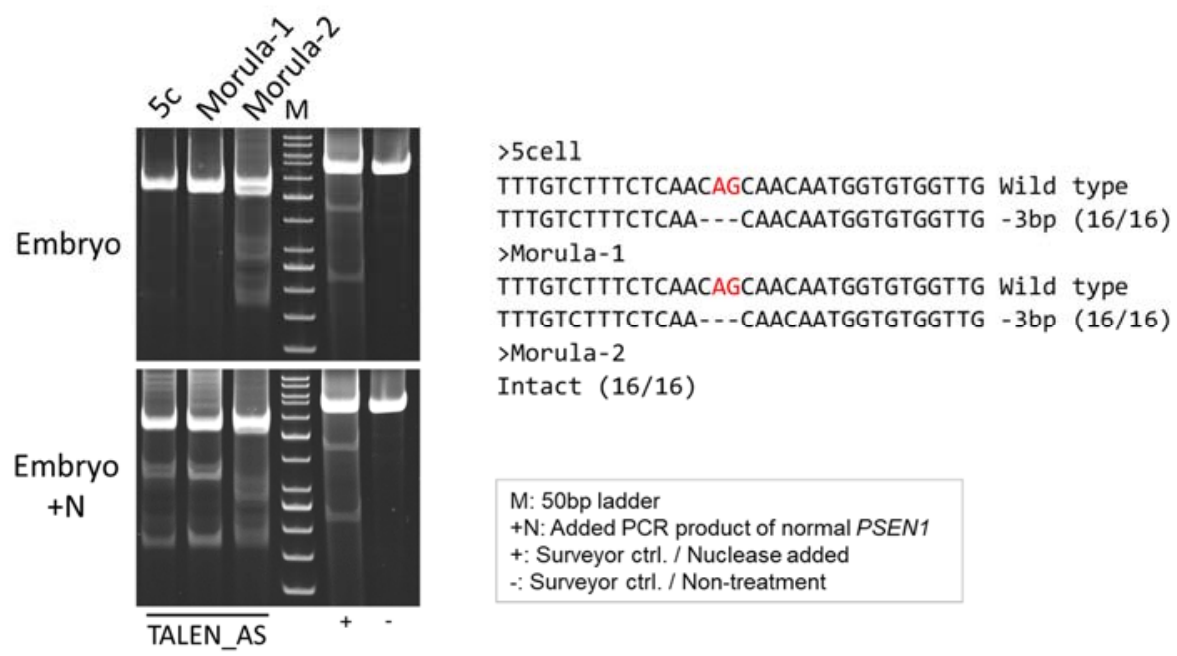

c)

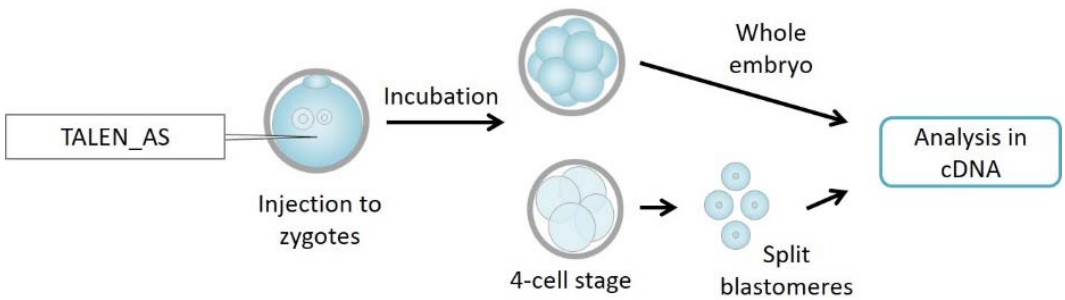

d)

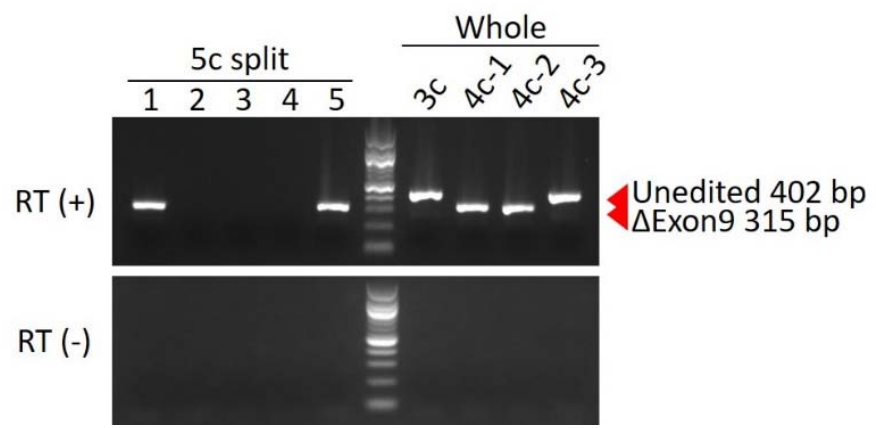

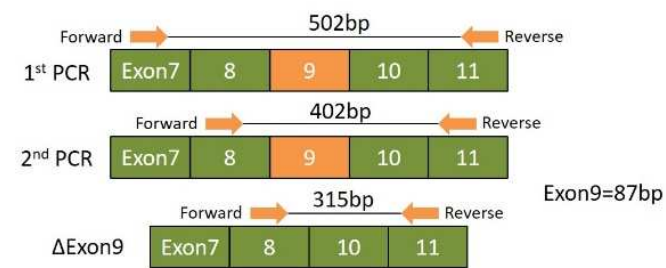




\section{Figure 1. TALEN-mediated genome editing in marmoset embryos.}

a) Left (TALEN_AS_L) and right (TALEN_AS_R) were constructed using Platinum Gate TALEN Kit (Addgene; cat\#10000000439) as previously described ${ }^{43}$. Pink boxes indicate TALEN targeting sites, green boxes indicate exons of the marmoset PSENI gene, and red letters (AG) are the acceptors site of exon 9. b) Surveyor assay of marmoset embryos after TALEN injection. PCR that covered the acceptor site of exon 9 in genomic DNA extracted from TALEN-injected embryos (left three columns) was performed with or without Nuclease $(\mathrm{N})$ treatment. The right two columns denoted experimental controls from wild-type embryos. c) Schematic representation of the TALEN mRNA injection and subsequent analysis of PSEN1 mRNA. After injection of TALEN mRNA into marmoset zygotes, RNA was extracted from four 3- to 4-cell stage whole embryos or single blastomeres from one 5-cell stage embryo after blastomere splitting. The RNA was reverse transcribed, and the cDNA was subjected to PCR (RT-PCR). d) RT-PCR of mRNA derived from TALEN-injected embryos. The lane 1-5 indicates RT-PCR products of each blastomere after splitting; the lanes 3c,4c-1, 4c-2, and4c-3indicate RT-PCR of four embryos without splitting. PCR products with exclusion of exon 9 appeared with 315 bp bands while wildtype bands were $402 \mathrm{bp}$. Note that all the analyzed embryos showed only single band, suggesting that no embryos carried the mutations in a heterozygous manner. 
Figure 2.

a)

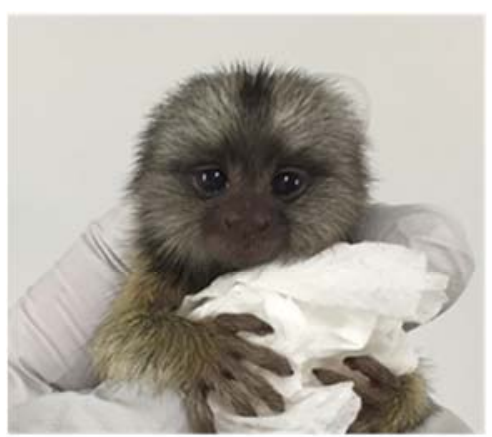

I774gmF

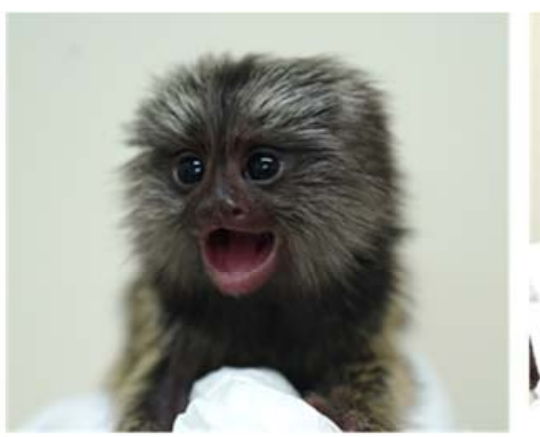

943gmM

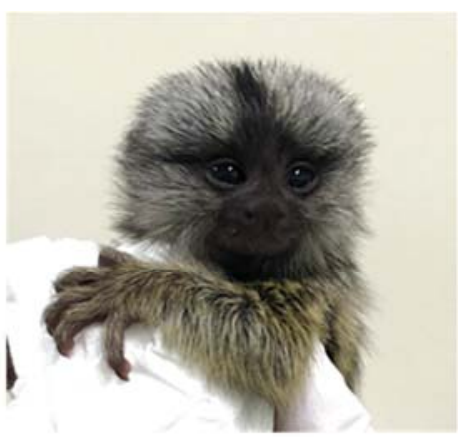

I949gmM

b)

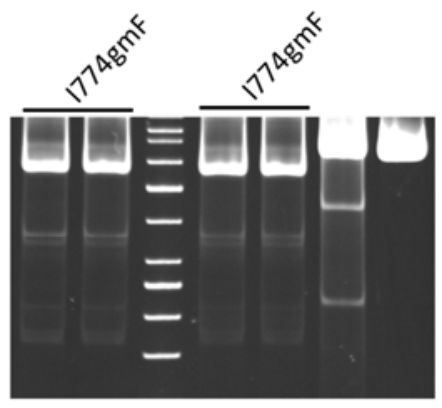

CB HR M

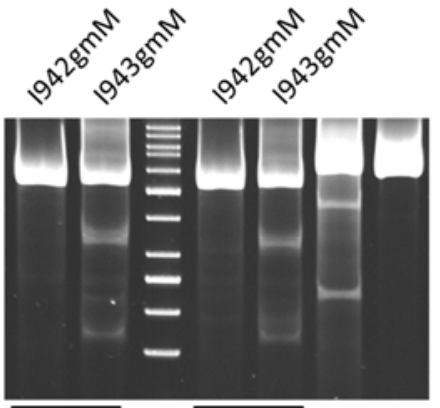

$\overline{\mathrm{HR}} \mathrm{M} \overline{\mathrm{HR}+\mathrm{N}}+-$

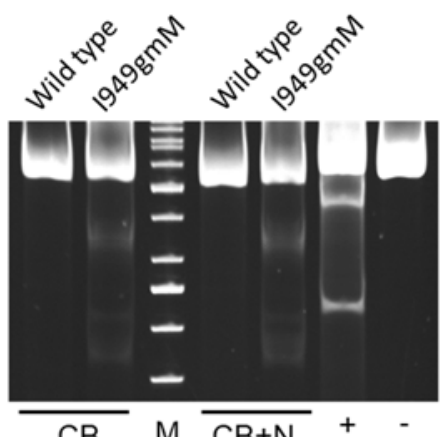

$\mathrm{CB} M \overline{\mathrm{CB}+\mathrm{N}}+$

CB: Cord blood genome

HR: Hair root genome

M: 50bp ladder

$+\mathrm{N}$ : Added PCR product of Normal PSEN1

+ : Surveyor ctrl. / Nuclease added

-: Surveyor ctrl. / Non-treatment

c)

\begin{tabular}{|c|c|}
\hline $\begin{array}{c}\text { Wild type } \\
\text { (1780gmF, 1940gmM 1942gmM) }\end{array}$ & TGCTTACCTGGAATTTTGTCTTTCTCAACAGCAACAATGGTGTGGTTGGTGAATATGGC Intact $(50 / 50)$ \\
\hline \multirow{2}{*}{$\begin{array}{c}\text { PSEN1- } \triangle E 9 \\
(\text { (1774gmF) }\end{array}$} & TGCTIACCTGGAATTTTGTCTTTCT--- CAACAATGGTATGGTTGGTGAATATGGC $-6 \mathrm{bp}(47 / 100)$ \\
\hline & TGCTIACCTGGAATTTTGTCTTTCTCAACAGCAACAATGGTGTGGTTGGTGAATATGGC Intact $(53 / 100)$ \\
\hline \multirow{2}{*}{$\begin{array}{c}\text { PSEN1- } \triangle E 9 \\
\text { (1943gmM) }\end{array}$} & TGCTIACCTGGAATTTTGTCTTTCT----CAACAATGGTATGGTTGGTGAATATGGC -6 bp $(41 / 100)$ \\
\hline & TGCTIACCTGGAATTTTGTCTTTCTCAACAGCAACAATGGTGTGGTTGGTGAATATGGC Intact $(59 / 100)$ \\
\hline \multirow{2}{*}{$\begin{array}{c}\text { PSEN1- } \triangle E 9 \\
\text { (1949gmM) }\end{array}$} & TGCTIACCTGGAATTTTGTCTTTCT--- CAATGGTATGGTTGGTGAATATGGC $-9 \mathrm{bp}(47 / 100)$ \\
\hline & TGCTIACCTGGAATTTTGTCTTTCTCAACAGCAACAATGGTGTGGTTGGTGAATATGGC Intact $(53 / 100)$ \\
\hline
\end{tabular}




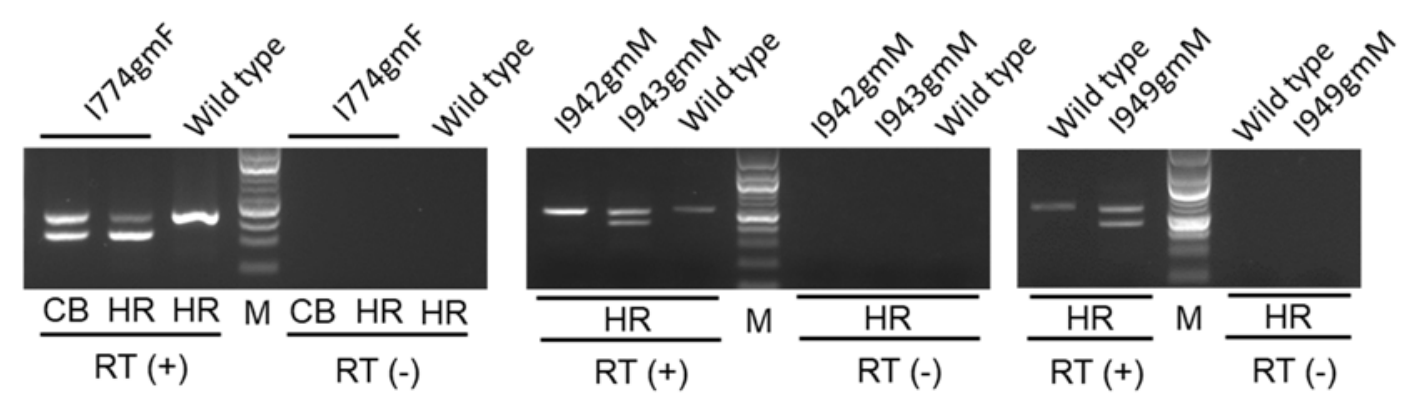

CB: Cord blood genome

HR: Hair root genome

M: 100bp ladder

$\mathrm{RT}(+)$ : Added reverse transcriptase

RT(-): Without reverse transcriptase

d)

\begin{tabular}{|c|c|c|c|}
\hline ID & Genotype & Wild type & $\Delta$ Exon9 \\
\hline I774gmF & PSEN1- $\triangle E 9$ & $46 \%(46 / 100)$ & $54 \%(54 / 100)$ \\
\hline I780gmF & Wild type & $100 \%(50 / 50)$ & $0 \%(0 / 50)$ \\
\hline I940gmM & Wild type & $100 \%(50 / 50)$ & $0 \%(0 / 50)$ \\
\hline I942gmM & Wild type & $100 \%(50 / 50)$ & $0 \%(0 / 50)$ \\
\hline I943gmM & PSEN1- $\triangle E 9$ & $43 \%(43 / 100)$ & $57 \%(57 / 100)$ \\
\hline |949gmM & PSEN1- $\triangle E 9$ & $42 \%(10 / 24)$ & $58 \%(14 / 24)$ \\
\hline
\end{tabular}

Figure 2. The PSEN1- $\triangle E 9$ marmosets generated by TALEN.

a) Photograph of the founder neonates. B) b) Surveyor assay of neonatal somatic tissues. Genomic DNAs extracted from umbilical cord blood and hair roots were subjected to surveyor assays. Samples, in which $4 \mu \mathrm{l}$ of the PCR product were mixed in equal amounts with the PCR product from wild-type PSEN1 DNA as a template to detect biallelic mutations in the PSEN1 gene, are designated as + N. c) Sequences of the TALEN-targeted site in PSENI gene. the underlined part corresponds to the TALEN recognition sequence: the red letters to the acceptor site, and the dashes to the missing bases. d) Result of sequence analyses of the neonates. RT-PCR products from hair roots obtained from 6 obtained neonates were subcloned and sequenced. The first column shows the marmoset identities, the second the genotypes, the $3^{\text {rd }}$ the percentage of wild-type cDNA, and the last percentage of mutated cDNA. 
Figure 3.

a)

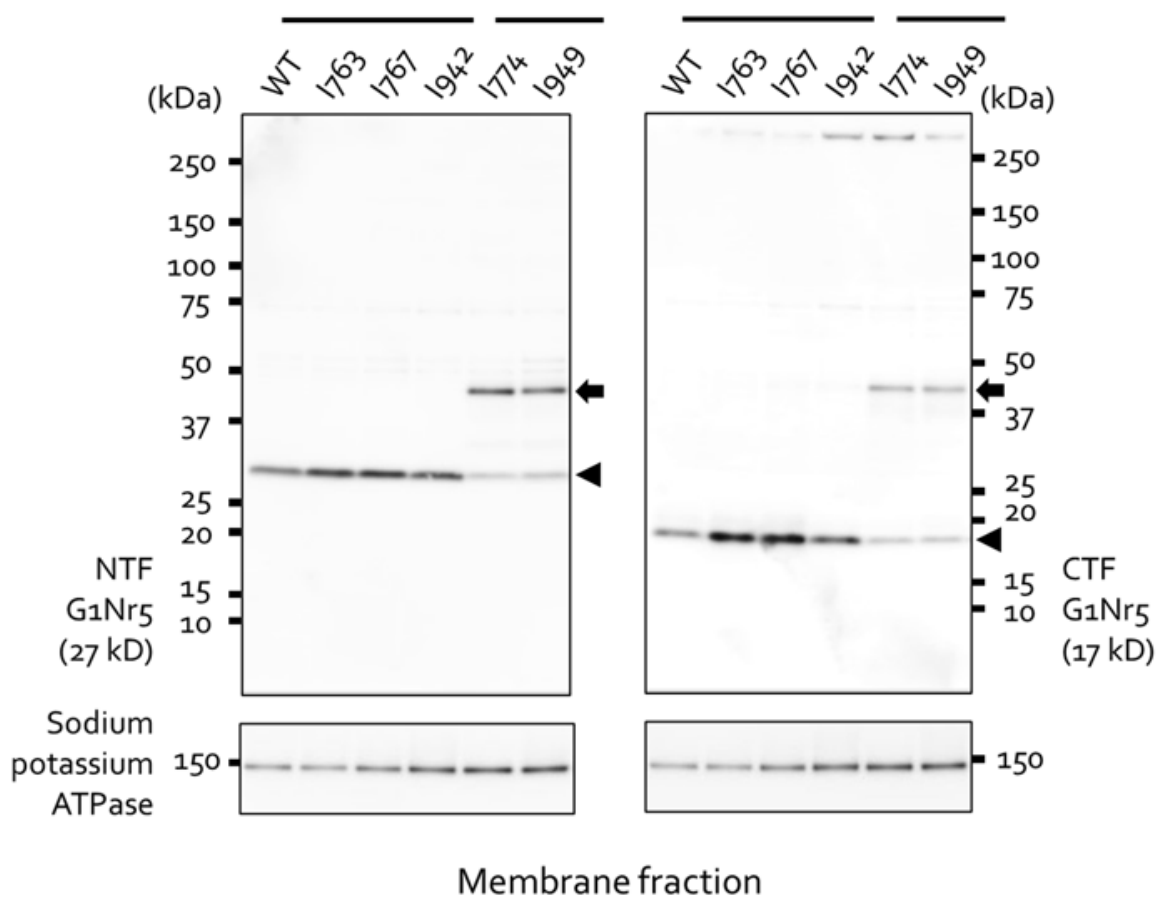

b)
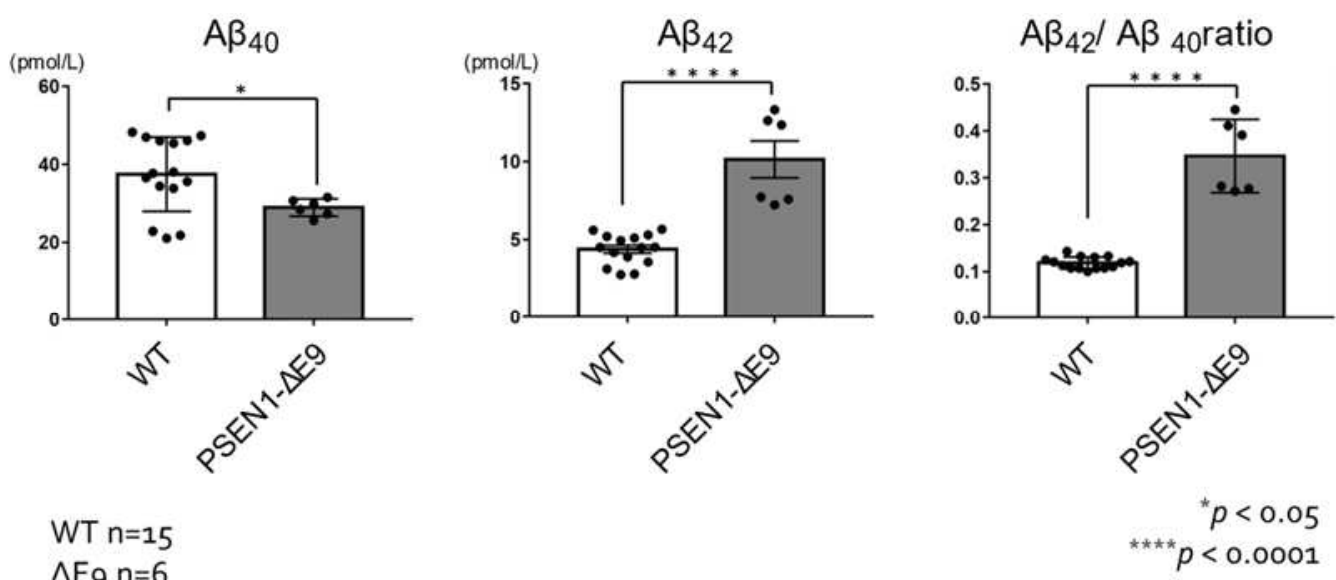

$\Delta \mathrm{Eg} n=6$

Figure 3. Biochemical analysis in the PSEN1- $\triangle E 9$ marmoset fibroblasts.

a) Western blot analysis of the membrane fractions obtained from wild-type (WT) and mutant $(\Delta \mathrm{E} 9)$ marmoset fibroblasts using antibodies to the N-terminal fragments (NTF) (left panel) and to Cterminal fragments (CTF) (right panel) of PS1. Arrowheads indicate NTF and CTF produced by endoproteolysis of PS1; arrows indicate uncleaved full-length PS1 protein. Sodium-potassium ATPase was used as a loading control of the membrane fraction. b) $A \beta_{40}$ and $A \beta_{42}$ in the culture media from 
wild-type and mutant marmoset fibroblasts were quantified by sandwitch ELISA. The A $\beta_{43}$ levels were below the detection limit. Data represent mean \pm sem $(\mathrm{n}=15$ (WT); $6(\Delta \mathrm{E} 9)) .{ }^{*} P<0.05$; $* * * * \mathrm{P}<0.0001$ (Student's two-tailed $t$-test). 
Table 1. Summary of animal generation

\begin{tabular}{|c|c|c|l|c|l|l|c|c|c|}
\hline $\begin{array}{l}\text { TALEN } \\
\text { injected } \\
\text { ova }\end{array}$ & $\begin{array}{l}\text { Matured } \\
\text { ova (\%) }\end{array}$ & $\begin{array}{l}\text { Fertilized } \\
\text { ova (\%) }\end{array}$ & $\begin{array}{l}\text { Transferred } \\
\text { embryos } \\
(\%)\end{array}$ & Recipients & $\begin{array}{l}\text { Pregnant } \\
\text { animals } \\
(\%)\end{array}$ & $\begin{array}{l}\text { Aborted } \\
\text { case } \\
(\%)\end{array}$ & $\begin{array}{l}\text { Delivered } \\
\text { animals }\end{array}$ & Intact & Mutant \\
\hline 810 & $\begin{array}{c}578 \\
(71.4)\end{array}$ & $\begin{array}{c}218 \\
(37.7)\end{array}$ & $154(70.6)$ & 77 & $7(9.1)$ & $2(28.6)$ & 6 & 3 & 3 \\
\hline
\end{tabular}




\section{References}

1 Crook, R. et al. A variant of Alzheimer's disease with spastic paraparesis and unusual plaques due to deletion of exon 9 of presenilin 1. Nature medicine 4, 452-455, doi:10.1038/nm0498-452 (1998).

2 Prihar, G. et al. Alzheimer disease PS-1 exon 9 deletion defined. Nature medicine 5, 1090, doi:10.1038/13383 (1999).

3 Smith, M. J. et al. Variable phenotype of Alzheimer's disease with spastic paraparesis. Annals of neurology 49, 125-129 (2001).

4 Dumanchin, C. et al. Biological effects of four PSEN1 gene mutations causing Alzheimer disease with spastic paraparesis and cotton wool plaques. Human mutation 27, 1063, doi:10.1002/humu.9458 (2006).

5 Le Guennec, K. et al. Deletion of exons 9 and 10 of the Presenilin 1 gene in a patient with Early-onset Alzheimer Disease generates longer amyloid seeds. Neurobiology of disease 104, 97-103, doi:10.1016/j.nbd.2017.04.020 (2017).

$6 \quad<$ World Alzheimer Report 2019.pdf>.

7 Winblad, B. et al. Defeating Alzheimer's disease and other dementias: a priority for European science and society. The Lancet. Neurology 15, 455-532, doi:10.1016/s14744422(16)00062-4 (2016).

8 Scheltens, P. et al. Alzheimer's disease. Lancet (London, England) 388, 505-517, doi:10.1016/s0140-6736(15)01124-1 (2016).

9 Bateman, R. J. et al. Clinical and biomarker changes in dominantly inherited Alzheimer's disease. The New England journal of medicine 367, 795-804, doi:10.1056/NEJMoa1202753 (2012).

10 Braak, H. \& Braak, E. Demonstration of amyloid deposits and neurofibrillary changes in whole brain sections. Brain pathology (Zurich, Switzerland) 1, 213-216, doi:10.1111/j.1750-3639.1991.tb00661.x (1991).

11 Hyman, B. T. et al. National Institute on Aging-Alzheimer's Association guidelines for the neuropathologic assessment of Alzheimer's disease. Alzheimer's \&amp; dementia : the journal of the Alzheimer's Association 8, 1-13, doi:10.1016/j.jalz.2011.10.007 (2012).

12 Selkoe, D. J. \& Hardy, J. The amyloid hypothesis of Alzheimer's disease at 25 years. EMBO Mol Med 8, 595-608, doi:10.15252/emmm.201606210 (2016).

13 Saito, T. et al. Single App knock-in mouse models of Alzheimer's disease. Nature neuroscience 17, 661-663, doi:10.1038/nn.3697 (2014).

14 Sasaguri, H. et al. APP mouse models for Alzheimer's disease preclinical studies. The EMBO journal 36, 2473-2487, doi:10.15252/embj.201797397 (2017). 
15 Hashimoto, S. et al. Tau binding protein CAPON induces tau aggregation and neurodegeneration. Nat Commun 10, 2394, doi:10.1038/s41467-019-10278-x (2019).

16 Jun, H. et al. Disrupted Place Cell Remapping and Impaired Grid Cells in a Knockin Model of Alzheimer's Disease. Neuron, doi:10.1016/j.neuron.2020.06.023 (2020).

17 Chen, W. T. et al. Spatial Transcriptomics and In Situ Sequencing to Study Alzheimer's Disease. Cell, doi:10.1016/j.cell.2020.06.038 (2020).

18 Masuda, A. et al. Cognitive deficits in single App knock-in mouse models. Neurobiol Learn Mem 135, 73-82, doi:10.1016/j.nlm.2016.07.001 (2016).

19 Nortley, R. et al. Amyloid beta oligomers constrict human capillaries in Alzheimer's disease via signaling to pericytes. Science 365, doi:10.1126/science.aav9518 (2019).

20 Saito, T. et al. Humanization of the entire murine Mapt gene provides a murine model of pathological human tau propagation. The Journal of biological chemistry 294, 1275412765, doi:10.1074/jbc.RA119.009487 (2019).

21 Li, S., Zhou, X., Constantinidis, C. \& Qi, X. L. Plasticity of Persistent Activity and Its Constraints. Front Neural Circuits 14, 15, doi:10.3389/fncir.2020.00015 (2020).

22 Sasaki, E. et al. Generation of transgenic non-human primates with germline transmission. Nature 459, 523-527, doi:10.1038/nature08090 (2009).

23 Izpisua Belmonte, J. C. et al. Brains, genes, and primates. Neuron 86, 617-631, doi:10.1016/j.neuron.2015.03.021 (2015).

24 Miller, C. T. et al. Marmosets: A Neuroscientific Model of Human Social Behavior. Neuron 90, 219-233, doi:10.1016/j.neuron.2016.03.018 (2016).

25 Geula, C., Nagykery, N. \& Wu, C. K. Amyloid-beta deposits in the cerebral cortex of the aged common marmoset (Callithrix jacchus): incidence and chemical composition. Acta neuropathologica 103, 48-58, doi:10.1007/s004010100429 (2002).

26 Rodriguez-Callejas, J. D., Fuchs, E. \& Perez-Cruz, C. Evidence of Tau Hyperphosphorylation and Dystrophic Microglia in the Common Marmoset. Frontiers in aging neuroscience 8, 315, doi:10.3389/fnagi.2016.00315 (2016).

27 Tardif, S. D., Mansfield, K. G., Ratnam, R., Ross, C. N. \& Ziegler, T. E. The marmoset as a model of aging and age-related diseases. ILAR journal 52, 54-65 (2011).

28 t Hart, B. A. \& Massacesi, L. Clinical, pathological, and immunologic aspects of the multiple sclerosis model in common marmosets (Callithrix jacchus). Journal of neuropathology and experimental neurology 68, 341-355, doi:10.1097/NEN.0b013e31819f1d24 (2009).

29 Ennerfelt, H. E. \& Lukens, J. R. The role of innate immunity in Alzheimer's disease. Immunol Rev, doi:10.1111/imr.12896 (2020).

30 Kellar, D. \& Craft, S. Brain insulin resistance in Alzheimer's disease and related disorders: 
mechanisms and therapeutic approaches. The Lancet. Neurology, doi:10.1016/s14744422(20)30231-3 (2020).

31 Rosario, D. et al. Systems Biology Approaches to Understand the Host-Microbiome Interactions in Neurodegenerative Diseases. Front Neurosci 14, 716, doi:10.3389/fnins.2020.00716 (2020).

32 Pyun, J. M., Kang, M. J., Yun, Y., Park, Y. H. \& Kim, S. APOE $\varepsilon 4$ and REM Sleep Behavior Disorder as Risk Factors for Sundown Syndrome in Alzheimer's Disease. J Alzheimers Dis 69, 521-528, doi:10.3233/jad-190032 (2019).

33 Crofts, H. S. et al. Investigation of the sleep electrocorticogram of the common marmoset (Callithrix jacchus) using radiotelemetry. Clinical neurophysiology : official journal of the International Federation of Clinical Neurophysiology 112, 2265-2273 (2001).

34 Sato, K. et al. Generation of a Nonhuman Primate Model of Severe Combined Immunodeficiency Using Highly Efficient Genome Editing. Cell stem cell 19, 127-138, doi:10.1016/j.stem.2016.06.003 (2016).

35 Scearce-Levie, K., Sanchez, P. E. \& Lewcock, J. W. Leveraging preclinical models for the development of Alzheimer disease therapeutics. Nat Rev Drug Discov 19, 447-462, doi:10.1038/s41573-020-0065-9 (2020).

36 Blauwendraat, C. et al. Pilot whole-exome sequencing of a German early-onset Alzheimer's disease cohort reveals a substantial frequency of PSEN2 variants. Neurobiology of aging 37, 208.e211-208.e217, doi:10.1016/j.neurobiolaging.2015.09.016 (2016).

37 Hutton, M. et al. Complete analysis of the presenilin 1 gene in early onset Alzheimer's disease. Neuroreport 7, 801-805 (1996).

38 Kwok, J. B. et al. Two novel (M233T and R278T) presenilin-1 mutations in early-onset Alzheimer's disease pedigrees and preliminary evidence for association of presenilin-1 mutations with a novel phenotype. Neuroreport 8, 1537-1542 (1997).

39 Brooks, W. S. et al. Alzheimer's disease with spastic paraparesis and 'cotton wool' plaques: two pedigrees with PS-1 exon 9 deletions. Brain : a journal of neurology 126, 783-791 (2003).

40 Steiner, H. et al. The biological and pathological function of the presenilin-1 Deltaexon 9 mutation is independent of its defect to undergo proteolytic processing. The Journal of biological chemistry 274, 7615-7618, doi:10.1074/jbc.274.12.7615 (1999).

41 Zhang, H. X., Zhang, Y. \& Yin, H. Genome Editing with mRNA Encoding ZFN, TALEN, and Cas9. Mol Ther 27, 735-746, doi:10.1016/j.ymthe.2019.01.014 (2019).

42 Sakuma, T. et al. Efficient TALEN construction and evaluation methods for human cell and animal applications. Genes Cells 18, 315-326, doi:10.1111/gtc.12037 (2013). 
43 Sakuma, T. et al. Repeating pattern of non-RVD variations in DNA-binding modules enhances TALEN activity. Scientific reports 3, 3379, doi:10.1038/srep03379 (2013).

44 Shen, J. et al. Skeletal and CNS defects in Presenilin-1-deficient mice. Cell 89, 629-639 (1997).

45 De Strooper, B. et al. Deficiency of presenilin-1 inhibits the normal cleavage of amyloid precursor protein. Nature 391, 387-390, doi:10.1038/34910 (1998).

46 De Strooper, B. et al. A presenilin-1-dependent gamma-secretase-like protease mediates release of Notch intracellular domain. Nature 398, 518-522, doi:10.1038/19083 (1999).

47 Wolfe, M. S. et al. Two transmembrane aspartates in presenilin-1 required for presenilin endoproteolysis and gamma-secretase activity. Nature 398, 513-517, doi:10.1038/19077 (1999).

48 Thinakaran, G. et al. Endoproteolysis of presenilin 1 and accumulation of processed derivatives in vivo. Neuron 17, 181-190, doi:10.1016/s0896-6273(00)80291-3 (1996).

49 Kageyama, R., Ohtsuka, T., Shimojo, H. \& Imayoshi, I. Dynamic regulation of Notch signaling in neural progenitor cells. Curr Opin Cell Biol 21, 733-740, doi:10.1016/j.ceb.2009.08.009 (2009).

50 Selkoe, D. \& Kopan, R. Notch and Presenilin: regulated intramembrane proteolysis links development and degeneration. Annu Rev Neurosci 26, 565-597, doi:10.1146/annurev.neuro.26.041002.131334 (2003).

51 Miller, N. A. et al. A 26-hour system of highly sensitive whole genome sequencing for emergency management of genetic diseases. Genome Med 7, 100, doi:10.1186/s13073015-0221-8 (2015).

52 Takasugi, N. et al. The role of presenilin cofactors in the gamma-secretase complex. Nature 422, 438-441, doi:10.1038/nature01506 (2003).

53 Lemere, C. A. et al. The E280A presenilin 1 Alzheimer mutation produces increased A beta 42 deposition and severe cerebellar pathology. Nature medicine 2, 1146-1150, doi:10.1038/nm1096-1146 (1996).

54 Levy-Lahad, E. et al. Candidate gene for the chromosome 1 familial Alzheimer's disease locus. Science 269, 973-977, doi:10.1126/science.7638622 (1995).

55 Scheuner, D. et al. Secreted amyloid beta-protein similar to that in the senile plaques of Alzheimer's disease is increased in vivo by the presenilin 1 and 2 and APP mutations linked to familial Alzheimer's disease. Nature medicine 2, 864-870, doi:10.1038/nm0896864 (1996).

56 Kumar-Singh, S. et al. Mean age-of-onset of familial alzheimer disease caused by presenilin mutations correlates with both increased Abeta42 and decreased Abeta40. Human mutation 27, 686-695, doi:10.1002/humu.20336 (2006). 
57 Kim, J. et al. Abeta40 inhibits amyloid deposition in vivo. J Neurosci 27, 627-633, doi:10.1523/jneurosci.4849-06.2007 (2007).

58 Saito, T. et al. Potent amyloidogenicity and pathogenicity of A $\beta$ 43. Nature neuroscience 14, 1023-1032, doi:10.1038/nn.2858 (2011).

59 Sasaguri, H. et al. Introduction of pathogenic mutations into the mouse Psen 1 gene by Base Editor and Target-AID. Nat Commun 9, 2892, doi:10.1038/s41467-018-05262-w (2018).

60 Wang, F. et al. Generation of a Hutchinson-Gilford progeria syndrome monkey model by base editing. Protein Cell, doi:10.1007/s13238-020-00740-8 (2020).

61 Kangas, B. D. \& Bergman, J. Touchscreen technology in the study of cognition-related behavior. Behav Pharmacol 28, 623-629, doi:10.1097/fbp.0000000000000356 (2017).

62 Dennis, E. L. \& Thompson, P. M. Functional brain connectivity using fMRI in aging and Alzheimer's disease. Neuropsychol Rev 24, 49-62, doi:10.1007/s11065-014-9249-6 (2014).

63 Mohan, A. et al. The Significance of the Default Mode Network (DMN) in Neurological and Neuropsychiatric Disorders: A Review. Yale J Biol Med 89, 49-57 (2016).

64 Takahashi, T. et al. Birth of healthy offspring following ICSI in in vitro-matured common marmoset (Callithrix jacchus) oocytes. PLoS One 9, e95560, doi:10.1371/journal.pone.0095560 (2014).

65 Tomioka, I. et al. Generating induced pluripotent stem cells from common marmoset (Callithrix jacchus) fetal liver cells using defined factors, including Lin28. Genes Cells 15, 959-969, doi:10.1111/j.1365-2443.2010.01437.x (2010).

66 Doyle, E. L. et al. TAL Effector-Nucleotide Targeter (TALE-NT) 2.0: tools for TAL effector design and target prediction. Nucleic Acids Res 40, W117-122, doi:10.1093/nar/gks608 (2012).

67 Hashimoto, S. et al. Endoplasmic reticulum stress responses in mouse models of Alzheimer's disease: Overexpression paradigm versus knockin paradigm. The Journal of biological chemistry 293, 3118-3125, doi:10.1074/jbc.M117.811315 (2018).

68 Tomita, T. et al. C terminus of presenilin is required for overproduction of amyloidogenic Abeta42 through stabilization and endoproteolysis of presenilin. J Neurosci 19, 1062710634, doi:10.1523/jneurosci.19-24-10627.1999 (1999).

69 Sato, C., Takagi, S., Tomita, T. \& Iwatsubo, T. The C-terminal PAL motif and transmembrane domain 9 of presenilin 1 are involved in the formation of the catalytic pore of the gamma-secretase. J Neurosci 28, 6264-6271, doi:10.1523/jneurosci.1163-08.2008 (2008). 


\section{Figures}

a)

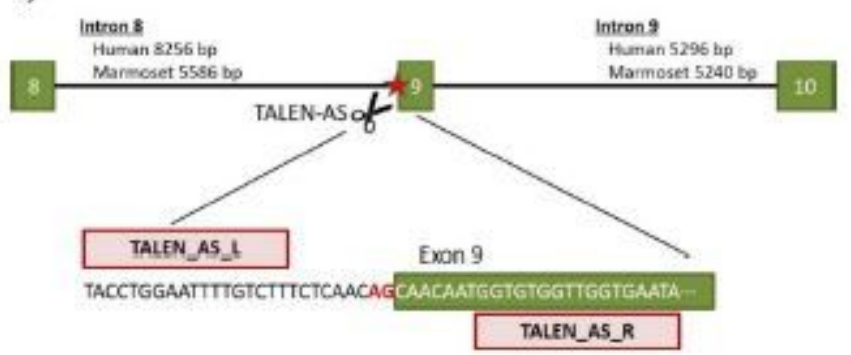

b)

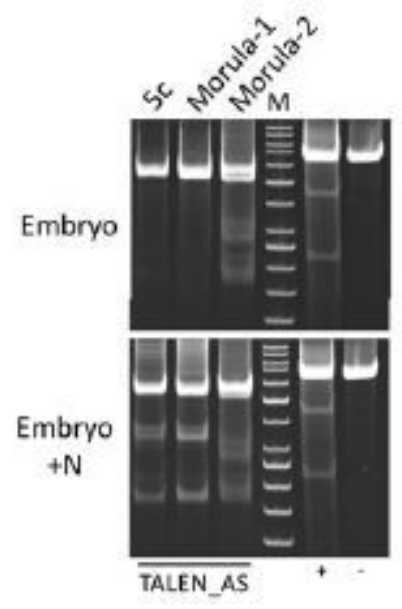

$>5 c e 11$

TITGTCTTTCTCAACAGCAACAATGGTGTGGTTG Wild type

TITGTCTTTCTCAA-.-CAACAATGGTGTGGTTG -3bp (16/16)

Morula-1

TITGTCTTTCTCAACAGCAACAATGGTGTGGTTG Wild type

TITGTCTTTCTCAA.... CAACAATGGTGTGGTTG -3bp (16/16)

Norula-2

Intact $(16 / 16)$

M. $50 \mathrm{bp}$ ladder

+ N. Added PCR product of normal PSENT

+ Sunveycr cirl. I Nuclease added

Sunveyor ctrl. / Non-trealment

c)

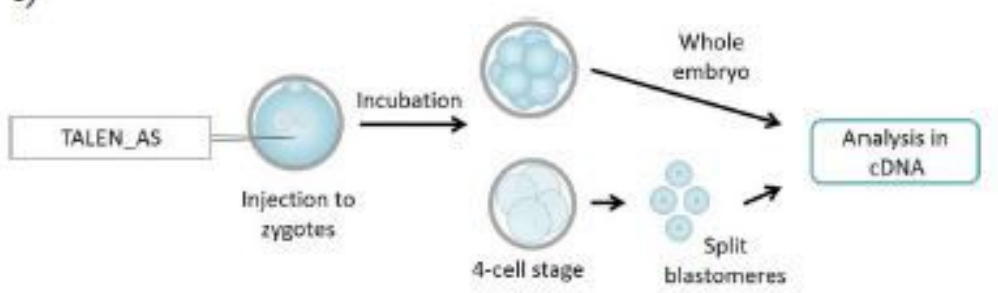

d)
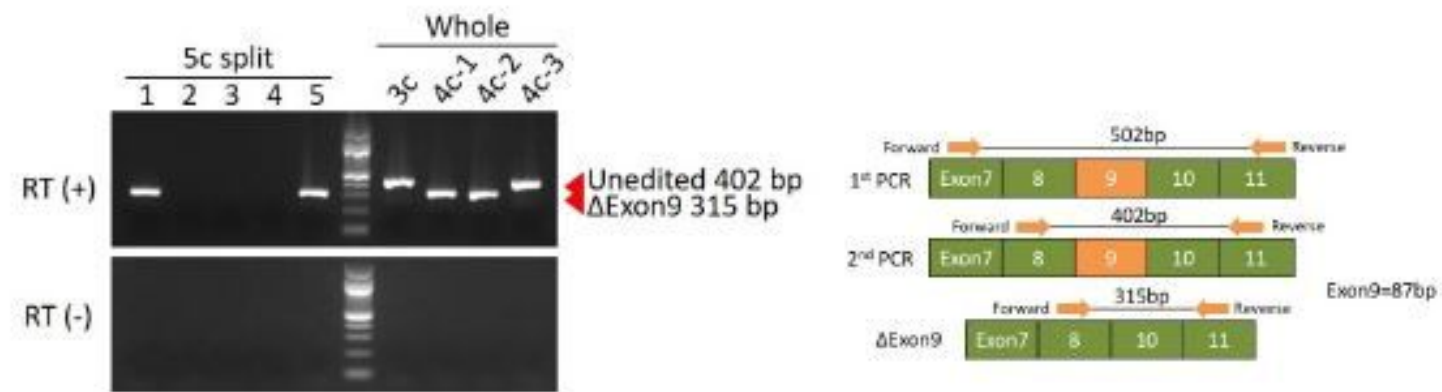

\section{Figure 1}

TALEN-mediated genome editing in marmoset embryos. a) Left (TALEN_AS_L) and right (TALEN_AS_R) were constructed using Platinum Gate TALEN Kit (Addgene; cat\#10000000439) as previously described43. Pink boxes indicate TALEN targeting sites, green boxes indicate exons of the marmoset 
PSEN1 gene, and red letters (AG) are the acceptors site of exon 9. b) Surveyor assay of marmoset embryos after TALEN injection. PCR that covered the acceptor site of exon 9 in genomic DNA extracted from TALEN-injected embryos (left three columns) was performed with or without Nuclease (N) treatment. The right two columns denoted experimental controls from wild-type embryos. c) Schematic representation of the TALEN mRNA injection and subsequent analysis of PSEN1 mRNA. After injection of TALEN mRNA into marmoset zygotes, RNA was extracted from four 3- to 4-cell stage whole embryos or single blastomeres from one 5-cell stage embryo after blastomere splitting. The RNA was reverse transcribed, and the cDNA was subjected to PCR (RT-PCR). d) RT-PCR of mRNA derived from TALENinjected embryos. The lane 1-5 indicates RT-PCR products of each blastomere after splitting; the lanes $3 c, 4 c-1,4 c-2$, and4c-3indicate RT-PCR of four embryos without splitting. PCR products with exclusion of exon 9 appeared with $315 \mathrm{bp}$ bands while wildtype bands were $402 \mathrm{bp}$. Note that all the analyzed embryos showed only single band, suggesting that no embryos carried the mutations in a heterozygous manner.

a)

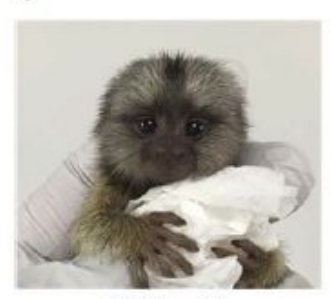

$1774 \mathrm{gmF}$

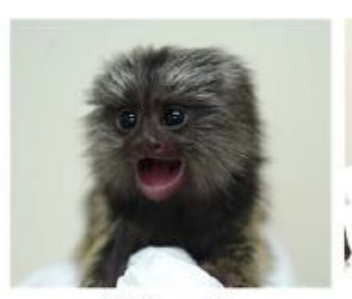

943gmM

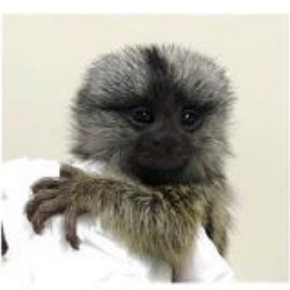

I949gmM b)

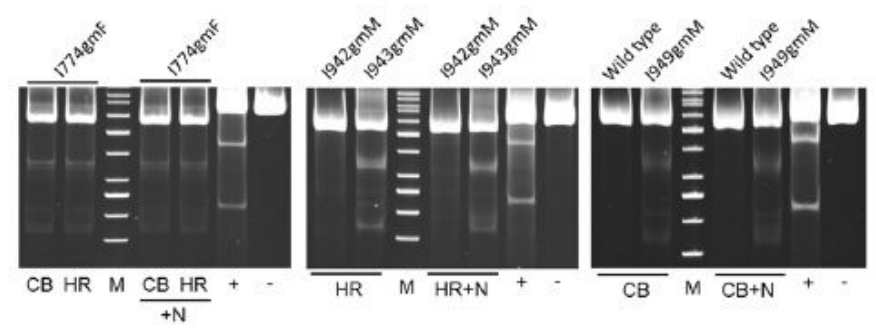

CB: Cord blood genome

HR: Hair root genome

M: $50 \mathrm{bp}$ ladder

$+\mathrm{N}$ : Added PCR product of Normal PSEN

+: Surveyor ctrl. / Nuclease added

$\therefore$ Surveyor ctrl. / Non-treatment

c)

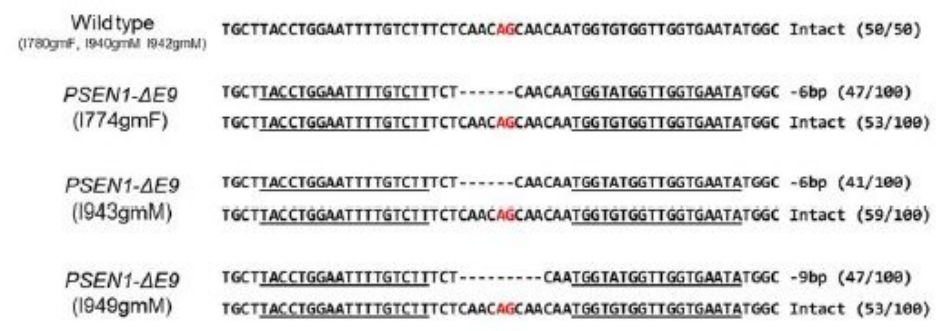

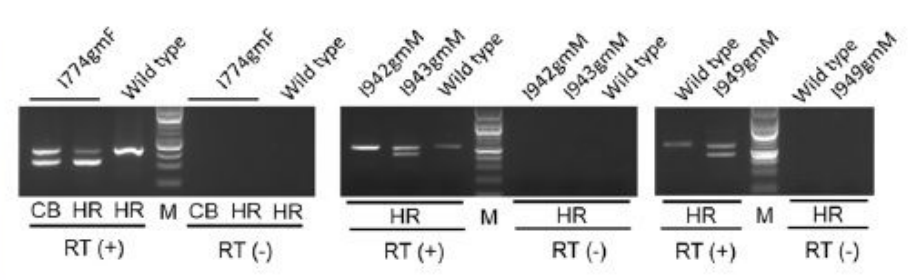

CB: Cord blood genome HR: Hair root genome M: 100bp ladder

$\mathrm{RT}(+)$ : Added reverse transcriptase

RT(-): Without reverse transcriptase

d)

\begin{tabular}{|c|c|c|c|}
\hline ID & Genotype & Wild type & $\Delta$ Exon9 \\
\hline I774gmF & PSEN1- $\triangle E 9$ & $46 \%(46 / 100)$ & $54 \%(54 / 100)$ \\
\hline $1780 \mathrm{gmF}$ & Wild type & $100 \%(50 / 50)$ & $0 \%(0 / 50)$ \\
\hline $1940 \mathrm{gmM}$ & Wild type & $100 \%(50 / 50)$ & $0 \%(0 / 50)$ \\
\hline I942gmM & Wild type & $100 \%(50 / 50)$ & $0 \%(0 / 50)$ \\
\hline I943gmM & PSEN1- $\triangle E 9$ & $43 \%(43 / 100)$ & $57 \%(57 / 100)$ \\
\hline 1949gmM & PSEN1- $\triangle E 9$ & $42 \%(10 / 24)$ & $58 \%(14 / 24)$ \\
\hline
\end{tabular}

Figure 2 
The PSEN1- $\triangle E$ 9 marmosets generated by TALEN. a) Photograph of the founder neonates. B) b) Surveyor assay of neonatal somatic tissues. Genomic DNAs extracted from umbilical cord blood and hair roots were subjected to surveyor assays. Samples, in which $4 \mu$ of the PCR product were mixed in equal amounts with the PCR product from wild-type PSEN1 DNA as a template to detect biallelic mutations in the PSEN1 gene, are designated as +N. c) Sequences of the TALEN-targeted site in PSEN1 gene. the underlined part corresponds to the TALEN recognition sequence: the red letters to the acceptor site, and the dashes to the missing bases. d) Result of sequence analyses of the neonates. RT-PCR products from hair roots obtained from 6 obtained neonates were subcloned and sequenced. The first column shows the marmoset identities, the second the genotypes, the 3rd the percentage of wild-type cDNA, and the last percentage of mutated cDNA.

a)

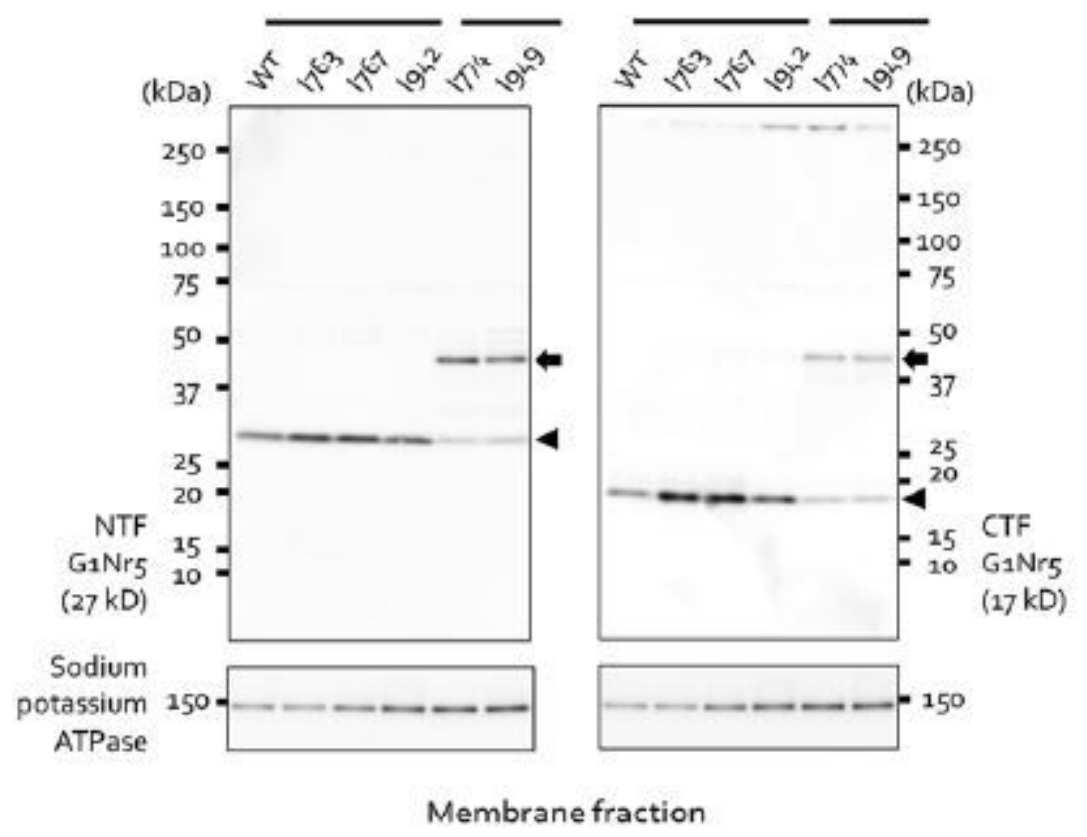

b)
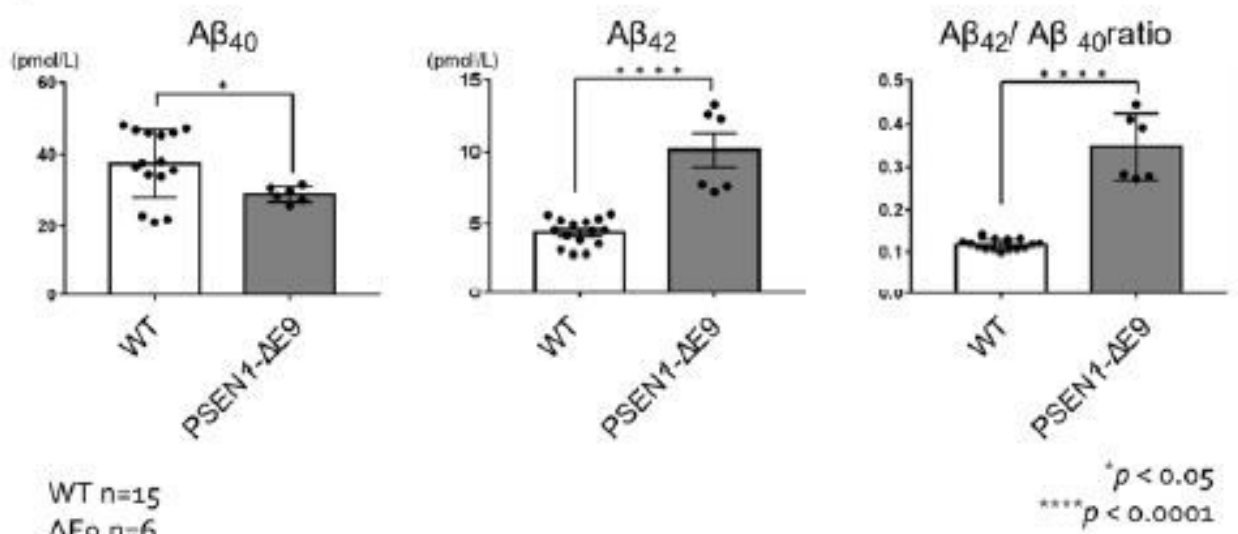

WT $n=15$

$\Delta E_{9} n=6$

\section{Figure 3}


Biochemical analysis in the PSEN1- $\triangle E 9$ marmoset fibroblasts. a) Western blot analysis of the membrane fractions obtained from wild-type (WT) and mutant (DE9) marmoset fibroblasts using antibodies to the Nterminal fragments (NTF) (left panel) and to Cterminal fragments (CTF) (right panel) of PS1. Arrowheads indicate NTF and CTF produced by endoproteolysis of PS1; arrows indicate uncleaved full-length PS1 protein. Sodium-potassium ATPase was used as a loading control of the membrane fraction. b) AB40 and $A \otimes 42$ in the culture media from 20 wild-type and mutant marmoset fibroblasts were quantified by sandwitch ELISA. The A₫43 levels were below the detection limit. Data represent mean \pm sem $(n=15$ (WT); $6\left(\right.$ (खE9)).. ${ }^{\star} \mathrm{P}<0.05 ;{ }^{\star \star \star *} \mathrm{P}<0.0001$ (Student's two-tailed t-test).

\section{Supplementary Files}

This is a list of supplementary files associated with this preprint. Click to download.

- Satoetal.SupplementaryNatAging210222.pdf 